\title{
Development of low cost paddy straw-clay (pads- clay) filter for dyes wastewater treatment
}

\begin{abstract}
Effective treatment of dyes wastewater is important to prevent water pollution. According to data by the Department of Environment (DOE) in 2017, 51 rivers have been polluted because of sewage, industry growth, livestock breeding and attitude of some irresponsible Malaysians that dump trash into river. One of the industries that contribute to river pollution is the batik industry. This is because batik processing activities have resulted in effluents containing chemicals streamed into the river and affecting aquatic life and human health as well. The main goals of this project is to produce a filter from available locally materials in solving polluted river water arising from batik wastewater. Along with the theme "from nature back to nature", PadS-Clay Filter were prepared from 100\% waste material such as paddy straw and clay according to designed formulation. Then, the dyes wastewater was flow on the PadS-Clay Filter and passed through the filter. The UV-Vis spectrophotometer was used to analyze the absorption and concentration of the filtered dyes wastewater. Based on the result, PadS-Clay 2 (PSC2) and PadS-Clay 3 (PSC 3) were the most effective designed formulation for dyes rejection and flux of dyes in treating dyes effluent as the percentage of the dyes rejection for all PSC2 were over than $90 \%$.
\end{abstract}

Keywords: textile wastewater, clay, paddy straw, water pollution, dyes rejection
Volume 5 Issue I - 2020

\author{
Abdul Rahman Hassan, ${ }^{1,2}$ Nor Amalina \\ Ab Rahim,' Mohd Talib Abdul Wahab, ${ }^{3}$ CE \\ Noor Aien CE Mahmood, ${ }^{3}$ Wan Salasiah \\ Wan Sulaiman, ${ }^{3}$ Fauziah Md Nor, ${ }^{3}$ Normi \\ Suhaida Jusoh, ${ }^{3}$ Najiah Hanim Hashim, ${ }^{3}$ \\ MN Shamsulainee Othman, ${ }^{3}$ Sharuddin \\ Mohamed $^{3}$ \\ 'Faculty of Innovative Design and Technology (FRIT), Universiti \\ Sultan Zainal Abidin (UniSZA), Malaysia \\ ${ }^{2}$ East Coast Environmental Research Institute (ESERI), Universiti \\ Sultan Zainal Abidin (UniSZA), Malaysia \\ ${ }^{3}$ Panji Innovation Laboratory (PILAB), Sekolah Menengah \\ Kebanggsaan Panji Alam (SMKPA), Malaysia
}

Correspondence: Abdul Rahman Hassan, Faculty of Innovative Design and Technology (FRIT), East Coast Environmental Research Institute (ESERI), Universiti Sultan Zainal Abidin, Gong Badak Campus, 21300 Kuala Nerus, Terengganu, Malaysia, Tel +609-6688069, Fax +609-6688707,

Email rahmanhassan@unisza.edu.my

Received: January 17, 2020 | Published: February 20, 2020
Abbreviations: DOE, department of environment; M1, concentration of raw sample; M2, concentration raw samples in this project; V1, volume of raw sample in this project; V2, volume of volumetric flask; $\mathrm{R}$, dyes rejection; $\mathrm{Cf}$, initial absorption; $\mathrm{Cp}$, final absorption; $\mathrm{V}$, final volume of dyes testing; $\mathrm{A}$, area of the pads-clay filter; $\Delta \mathrm{T}$, times taken for the testing process, $\mathrm{MB}$, methyl blue; $\mathrm{RR}$, reactive red; and $\mathrm{RB}$, reactive black

\section{Introduction}

The number of contaminated rivers in Malaysia is increasingly in line with the growth of country's industry. According to data by the Department of Environment (DOE) in 2017, 51 rivers have been polluted because of sewage, industry development, livestock breeding and attitude of some irresponsible Malaysians who dump trash into the rivers. ${ }^{1}$ One of the major industries that contribute to river pollutions is the textile industry. The industry, especially the batik, is one of the traditional industries that have contributed to the country's economic growth. Every year, 280,000 tons of textile colours were estimated to be released in the textile industry. ${ }^{2}$

Batik cloth is a fabric that is processed by drawing, printing, colouring and dipping the fabric using physical barrier material on wax-like fabrics (to prevent parts applied by the candles are infused with colour) and the dispose of the physical obstruction (candle) to reveal the pattern. All these processes require at least 100 litres of water for each of the fabric. ${ }^{3}$ In Malaysia, most of the batik is composed of large, light and brightly coloured flower pattern motives. Because of this uniqueness, Malaysian batik is getting high demand from local and overseas markets.
However, batik processing activities that produce wastewater or dyes effluent have caused water pollution in Malaysia especially the State Terengganu. ${ }^{4}$ Approximately; $80 \mathrm{~L}$ of water are needed to produce $1 \mathrm{~kg}$ of fabric. At values of $150 \mathrm{~L}, 80 \%$ of this volume is discarded as effluent and only $12 \%$ of the total is the result of evaporation losses. ${ }^{5}$ This is because batik processing activities involve the use of many chemicals such as remazol and premazin which categorized as a type of dyes ${ }^{2}$ and also contain high $\mathrm{pH}(\mathrm{pH} 13)$. Effluent wastewater also contains suspended solids, organic and non-organic dyes that can also have an adverse effect on the environment and human health.

Various ways of treatment have been conducted by the previous researchers to find the best method in treating effluent. But still now, the problem has not been solved and the cost of implementation is also high. Among the technologies that introduced ware carbon adsorption, ${ }^{6}$ ozone treatment or UV treatment, membrane process (using ultra filter, micro filter, nano-filter and reverse osmosis), coagulation and flocculation. ${ }^{2,7}$ In addition, existing clay filters that are made up from clay and sawdust mixtures, ${ }^{8-10}$ mixtures of clay and rice husk ${ }^{11}$ and filter that made up from mixtures of clay and snail shells ${ }^{12}$ were also used in treating effluents. Most of the technologies involved a million of cost. Based on the research in 2016, Johor government for example has allocated over 100 million ringgits to treat contaminated river water by stage. ${ }^{13}$ Besides, all these treatment technologies involved high energy consumption and huge amount of chemical. The previous result also showed that these treatment technologies can only reduce the chemical composition of effluents.,11

The raw materials used for the preparation of PadS-Clay Filter are clay and paddy straw. The potential use of the paddy straw and clay as the material in treating textile wastewater was very convenient. 
Along with the theme "from nature back to nature", this project used $100 \%$ organic and green materials without any presence of chemical substances. This is because these materials were not only abundant materials but also low cost and considered as efficient and sustainable technologies for the treatment of textile wastewater. Use of paddy straw can minimize environmental problems such as air pollution and water pollution, while clay was used as it exhibits high plasticity to hold the filter particles together and has a higher dry mechanical strength when fired. The main aim of this project is to produce a filter from locally available materials such as paddy straw and clay for solving polluted river water, arising from batik wastewater.

\section{Material and methods}

\section{Raw material selection}

The main materials for fabrication process of PadS-Clay Filter were clay, paddy straw and water. The local clays were collected from two different nearby rivers that are Sungai Ibai and Sungai Linggi. The clays were preferred because it exhibits good characters to hold the filter particles together and it changes chemically to become a strong porous material when fired in the furnace. Paddy straw, was obtained from nearby paddy fields in Kampong Bukit Payung and used as the combustible material because it causes no bloating and results in more uniform distribution of pore size in the filters as well as increased the porosity of the PadS-Clay Filter. ${ }^{12}$ The tap water was used to mix the clay and paddy straw together to form a PadS-Clay final product. At PILAB, four different formulation of PadS-Clay were prepared. In order to produce the best PadS-Clay filter, different weight of clay and paddy straw were analyzed. Moreover, the heating duration as final calcination process was also studied.

\section{Dual layer PadS-Clay Filter design}

First of all, the raw material such as clays and paddy straw were collected. Each of the raw materials were subjected to various physical treatments process such as drying, crushing, grinding and sieving processes for the PadS-Clay filter preparation. The obtained dry raw clay was crushed using a mortar and pestle while paddy straw was cut into smaller pieces. The paddy straw was then grinded using a simple dry grinder. In order to get fine paddy straw powder, the grinded paddy straw was sieved using $60 \mu \mathrm{m}$ of sievers. As both of these materials are transformed into fine powder form, the clay powder and paddy straw were weighed based on the designed formulations and mixed together with water to form dough. The dough was then will be shaped based on the cylinder mould with outer diameter (OD) of $200 \mathrm{~mm}$ and thickness of $35 \mathrm{~mm}$. The PadS-Clay mould was showed as in Figure 1.

As the PadS-Clay comprises of dual layer, the formulation of these two layers are varied in the aspect of paddy straw, clay and water content based on designed formulations as in Table 1. For the upper layer, Sungai Linggi Clay was mixed with water while for bottom layer; Sungai Ibai Clay was mixed with paddy straw and water. Then, it will be dried under the sun for 3 days and fired in the furnace with the temperature of $500^{\circ} \mathrm{C}$ up to three hours to remove excessive water and to strengthen the Pads-Clay structure from any crack during the heating process. The entire process for the making of PadS-Clay Filter was depicted in Figure 2. Eventually, the final PadS-Clay Filter with dual layer of cross section as was depicted in Figure 3.

\section{Experimental method}

Raw samples of dyes such as Methyl Blue, Reactive Red and
Reactive Black were obtained from the most popular textile company, Noor Arfa Batik \& Craft in Chendering, Terengganu. The samples were then analyzed in the laboratory. First of all, the raw samples were prepared based on the concentrations needed to be $350 \mathrm{ppm}$ and $500 \mathrm{ppm}$, using the following equation:

$$
M_{1} V_{1}=M_{2} V_{2}
$$

Where $M_{1}$ and $M_{2}$ are the concentration of raw samples and the needed concentration of dyes for this project, respectively. In this study, the concentration of raw samples was fixed from the ranges of $900000 \mathrm{ppm}$ for those three types of dyes such as Methyl Blue, Reactive Red and Reactive Black. While, $V_{1}$ and $V_{2}$ are the volume for the needed concentration of this project and the volume of volumetric flask $(500 \mathrm{ml})$, respectively. The raw samples of dyes were then flow on the PadS-Clay Filter for the filtration process. During the filtration process dyes water passed through the filter by gravitational force, filtered water is then collected and analyzed using standard methods.

Table I Formulation of dual layer PadS-Clay Filter

\begin{tabular}{lllll}
\hline \multirow{2}{*}{ Materials } & \multicolumn{4}{c}{ PadS-Clay (PSC) formulations } \\
\cline { 2 - 5 } & PSC I & PSC 2 & PSC 3 & PSC 4 \\
\hline Clay Sungai lbai (g) & 650 & 650 & 630 & 630 \\
$\begin{array}{l}\text { Clay Sungai Linggi (g) } \\
\text { Paddy straw (g) }\end{array}$ & 450 & 450 & 450 & 450 \\
$\begin{array}{l}\text { Volume of water for } \\
\text { upper layer (ml) }\end{array}$ & 200 & 200 & 200 & 200 \\
$\begin{array}{l}\text { Volume of water for } \\
\text { bottom layer (ml) }\end{array}$ & 250 & 250 & 250 & 250 \\
$\begin{array}{l}\text { Duration of heating in } \\
\text { furnace (hrs) }\end{array}$ & 2 & 3 & 2 & 3 \\
$\begin{array}{l}\left.\text { Furnace temperature ( }{ }^{\circ} \mathrm{C}\right) \\
\text { Fure }\end{array}$ & 500 & 500 & 500 & 500 \\
\hline
\end{tabular}

\section{Note: PSC, PadS-Clay}

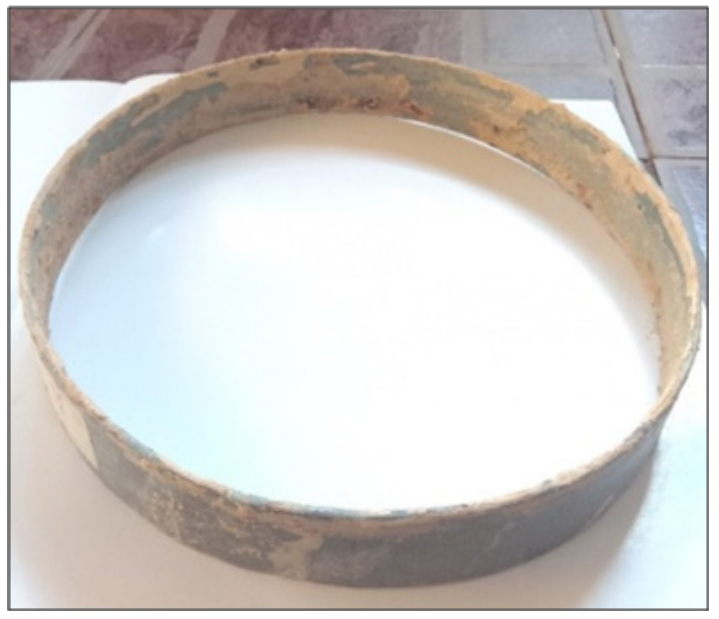

Figure I PadS-Clay Mould.

\section{Dyes wastewater analysis}

Filtered dyes wastewater was analyzed based on the parameters 
such as flux of dyes $\left(\mathrm{L} / \mathrm{m}^{2} \mathrm{~h}\right)$, dyes rejection (\%) and colour of treated dyes wastewater. The UV-Vis spectrophotometer was used to measure the concentration and absorption of the filtered dyes wastewater. While, flux of dyes was calculated based on the following Equation:

$$
\operatorname{Flux}\left(L / m^{2} h\right)=V /(A . \Delta t)
$$

Where $V$ the final volume of filtered dyes wastewater (L) is, $A$ is the area of the PadS-Clay $\left(\mathrm{m}^{2}\right)$ and $\Delta t$ is the time taken for the filtration process (hrs). The area for the PadS-Clay was constant, which is $0.0158 \mathrm{~m}^{2}$. Then, dyes rejection was calculated based on the following Equation:

$$
\text { Dyes Rejection, } R(\%)=\left(C_{f}-C_{p}\right) / C_{f} \times 100
$$

Where $C_{f}$ and $C_{p}$ are the initial and final dyes wastewater absorbance, respectively.
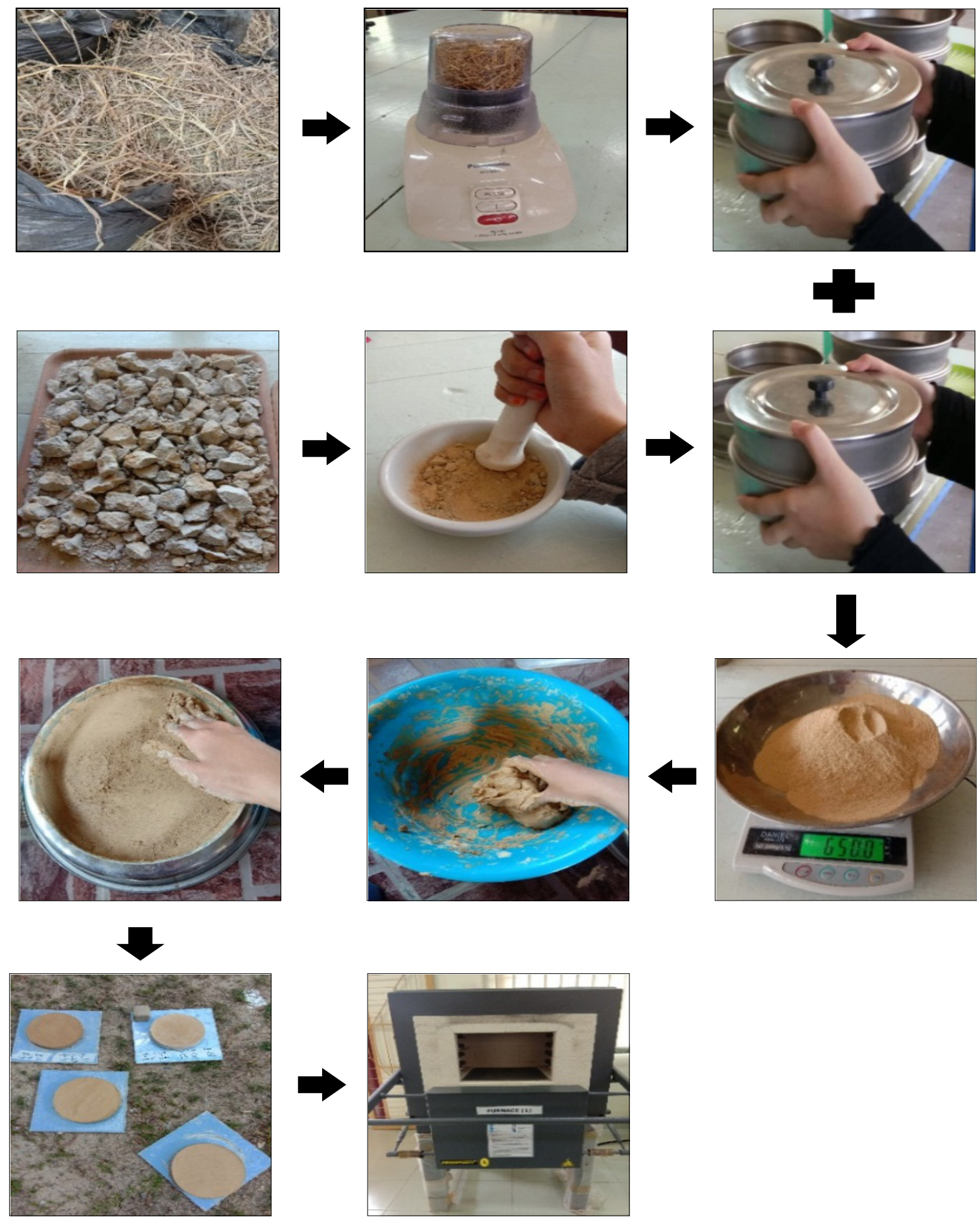

Figure 2 The making process of PadS-Clay Filter in PILAB.

Citation: Hassan AR, Rahim NAA, Wahab MTA, et al. Development of low cost paddy straw-clay (pads-clay) filter for dyes wastewater treatment. MOJ Eco Environ Sci. 2020;5(I):42-47. DOI: 10.15406/mojes.2020.05.00175 


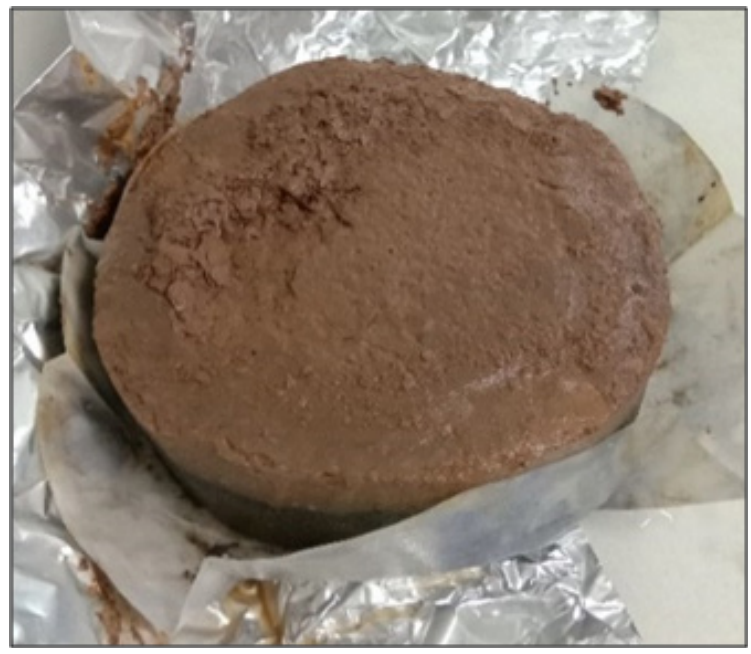

Figure 3 Final and cross-section of dual layer PadS-Clay Filter.

\section{Results and discussion}

\section{Flux of dyes}

Figure 4 shows the fluxes data for the Methyl Blue (MB) dyes at the concentration of $350 \mathrm{ppm}$ and $500 \mathrm{ppm}$. The fluxes showed almost the similar trend for both dyes concentration. At 350ppm of MB dyes concentration, the PSC 3 demonstrated the highest flux of about $10.02 \mathrm{~L} / \mathrm{m}^{2} \mathrm{~h}$. Meanwhile, at 500ppm, the PSC2 showed the highest flux of about $6.66 \mathrm{~L} / \mathrm{m}^{2} \mathrm{~h}$. These results indicated that both PSC2 and PSC 3 having the most porous structures compared to others PSC. In addition, the experimental data found that the PSC4 exhibited the lowest flux for both MB dyes concentrations. This trend might be due to the formation of narrower pores inside the PSC4 which led to the lower porosity character. This result was found similar as reported by other researcher. ${ }^{14}$

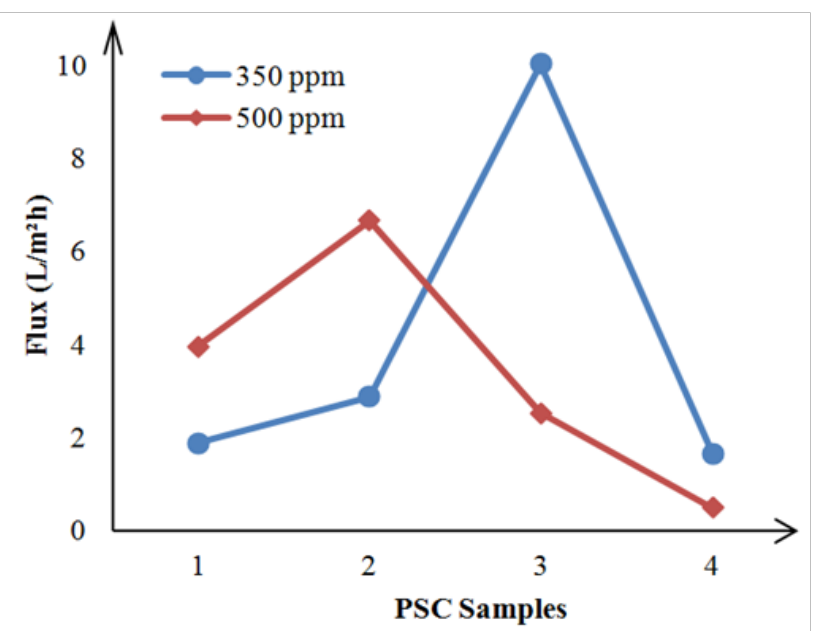

Figure 4 Fluxes of Methyl Blue (MB) dyes at different concentration for different PadS-Clay (PSC).

The fluxes data for the Reactive Red (RB) dyes was presented in Figure 5. From the result, it was found that the PSC2 and PSC3 achieved the highest flux of $11.2 \mathrm{~L} / \mathrm{m}^{2} \mathrm{~h}$ and $17.4 \mathrm{~L} / \mathrm{m}^{2} \mathrm{~h}$ for the RB dyes concentration of $350 \mathrm{ppm}$ and $500 \mathrm{ppm}$, respectively. The results

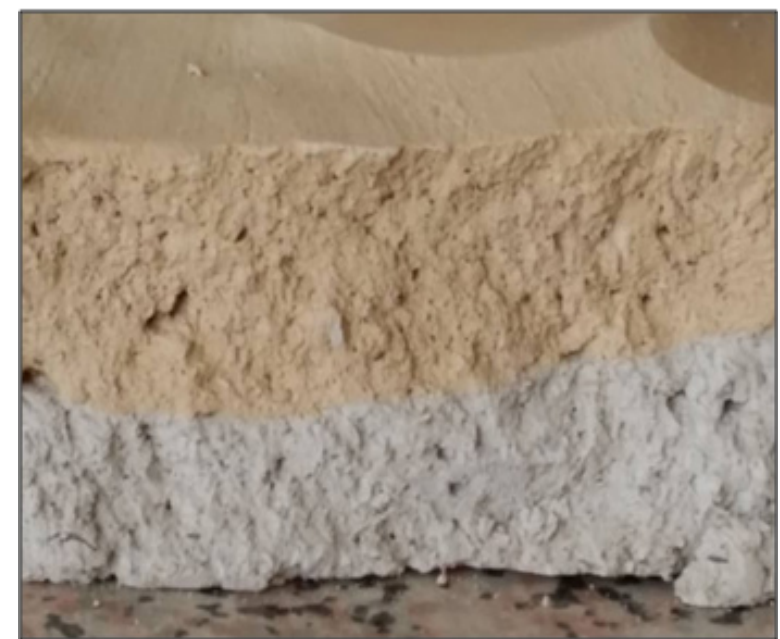

also showed that the PSC4 exhibited the lowest flux for RB dyes for both dyes concentration which were also very close to the results reported Shiravaju. ${ }^{15}$

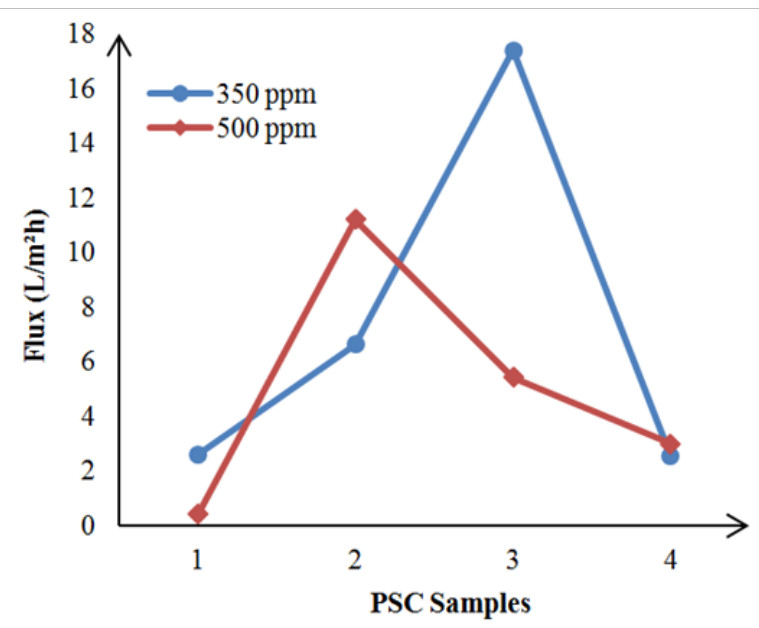

Figure 5 Fluxes of Dyes for Reactive Red (RR) dyes at different concentration for different PadS-Clay (PSC).

Among the three types of dyes, Reactive Black (RB) showed the highest value of flux, which was over $20 \mathrm{~L} / \mathrm{m}^{2} \mathrm{~h}$. Based on data in Figure 6, the PSC3 and PSC4 demonstrated the highest value of flux which are $21.2 \mathrm{~L} / \mathrm{m}^{2} \mathrm{~h}$ and $22.15 \mathrm{~L} / \mathrm{m}^{2} \mathrm{~h}$ for the concentration of $350 \mathrm{ppm}$ and $500 \mathrm{ppm}$, respectively. At $350 \mathrm{ppm} \mathrm{RB}$ dyes concentration, the fluxes showed similar trend compared to others dyes. However, at $500 \mathrm{ppm}$, the fluxes revealed a different trend, which was contrast to other dyes. The fluxes were decreased by PSC2 and then increased to the highest fluxes performed by PSC3 and PSC4, which are similar to the previous study by other researcher. ${ }^{16}$ Due to the highest value for dyes flux compared to other samples, it can be concluded that the PSC3 is the most porous clay for the dyes treatment process.

\section{Dyes rejection}

Figure 7 shows the rejection of MB dyes at the concentration of 
350ppm and 500ppm. PSC2 and PSC3 demonstrated the highest dyes rejection of about $93.86 \%$ and $89.84 \%$, respectively. The PSC 3 has the effective designed formulation for dyes rejection at $350 \mathrm{ppm}$ because the presence of high percentage of paddy straw and clay compared to other filters. Shivaraju et al. ${ }^{15}$ reported that, the higher amounts of clay in the clay product led towards the higher efficiency and performance.

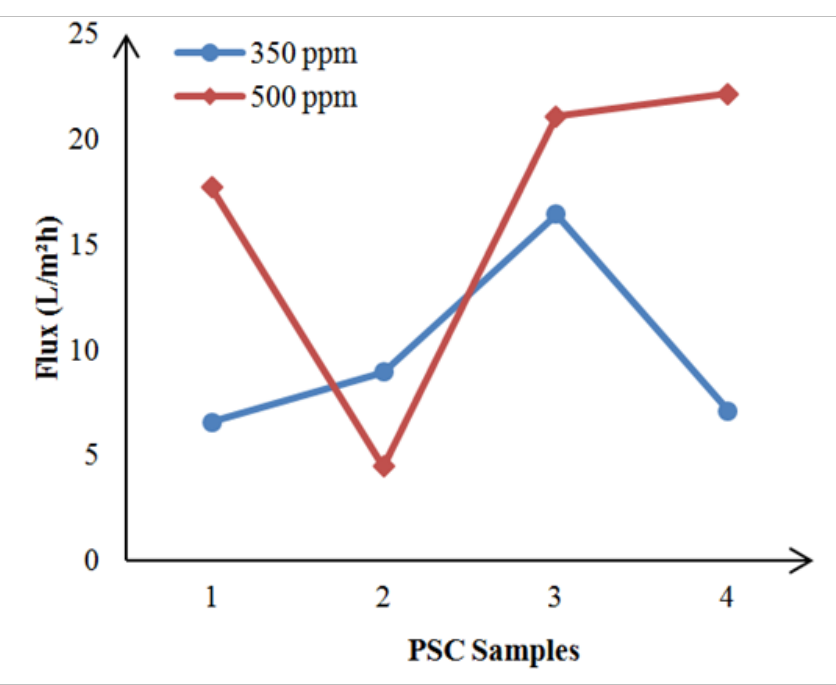

Figure 6 Fluxes of Dyes for Reactive Black (RB) dyes at different concentration for different PadS-Clay (PSC).

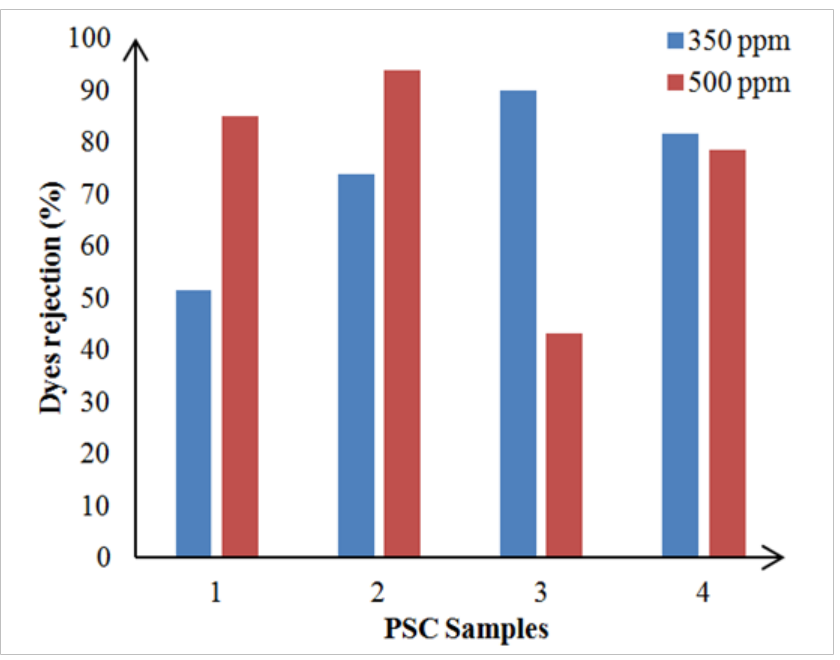

Figure 7 Dyes Rejection for Methyl Blue (MB) dyes at different concentration for different PadS-Clay (PSC).

For the Reactive Red dyes, the PSC2 showed the highest percentage of dyes rejection which are $94.93 \%$ and $95.59 \%$ at the concentration of $350 \mathrm{ppm}$ and $500 \mathrm{ppm}$, respectively (Figure 8). These trend probably contributed by the effect of heating treatment duration. As these clays go through the heating treatment from 2 to $3 \mathrm{hrs}$, the final structures of these clays become more interconnected and form narrower pores. It was stated that the paddy straw which mixed with the clay burnout during firing, made the filter porous thereby allowing water to pass through it. The pores in the filter blocked the microbes and particles from flowing through the PadS-Clay Filter and made the water produced free of dirt and color. ${ }^{12}$

In addition, Reactive Black shows the highest percentage of dyes rejection for all the PSC samples which is over than $85 \%$. The PSC2 achieved the highest dyes rejection of $98.25 \%$ and $97.81 \%$ for the concentration of $350 \mathrm{ppm}$ and $500 \mathrm{ppm}$, respectively (Figure 9). It was revealed that the most effective PadS-Clay for the dyes rejection is PSC2 as it has the highest percentage of dyes rejection which is over $90 \%$. The results of dyes removal from these fabricated PSC were found to be similar with the result of dyes removal reported by Shahadat and Isamil ${ }^{17}$ when the clay was used as absorbate materials for oil treatment.

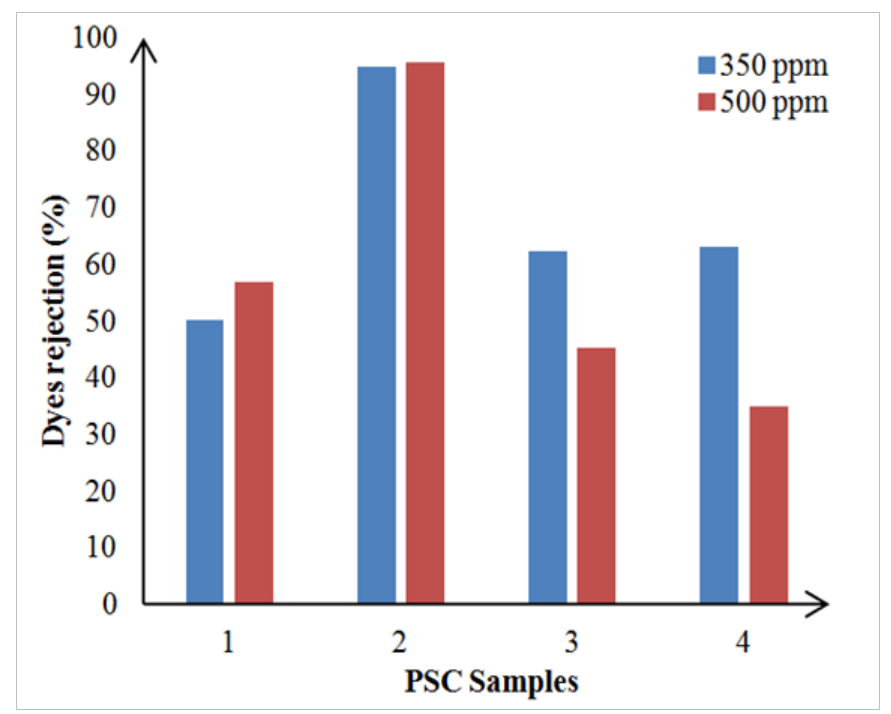

Figure 8 Dyes Rejection for Reactive Red (RR) dyes at different concentration for different PadS-Clay (PSC).

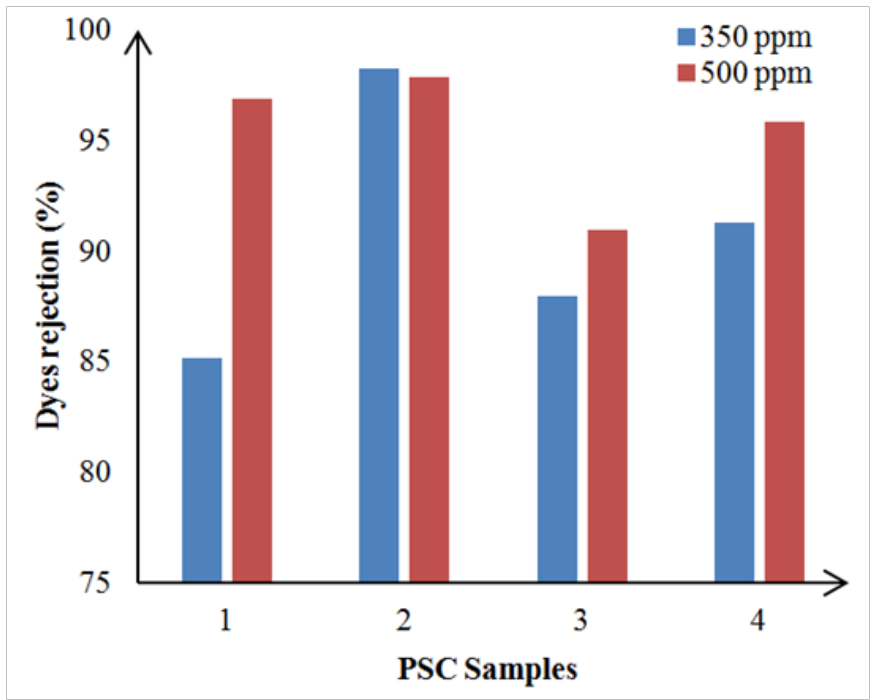

Figure 9 Dyes rejection for Reactive Black (RB) dyes at different concentration for different PadS-Clay (PSC).

\section{Conclusion}

This study demonstrated the potential use of clay and paddy straw as an alternative material in solving the dyes effluent problem. From the result, it can be concluded that the use of paddy straw and clay as the filter could be effective for treating polluted river wastewater containing textile dyes. PSC2 and PSC 3 appered to be the most effective designed formulation for treating dyes rejection 
and flux of dyes. Experimental data also revealed that the most effective PadS-Clay Filter for the dyes rejection is PSC2 as it has the highest percentage of dyes rejection, which is over $90 \%$. The results indicated that the local clays are having a great potential to be used of as filter media as well as the paddy straw bio-waste materials from agricultural industry also offered an good properties in supporting the sustainability and environmental conservation process.

\section{Acknowledgments}

The authors wish to express their highest gratitude to the "Outstanding 5 Innovation Students" Abi Aamar Arshad, Rushdina Sofea Rushdan, Roslan, Nur Salsabila Abdul Rahman, Siti Nabilah Syahirah and Muhammad Ajwad Mohd Zamri from Panji Innovation Lab (PiLAB) Team, Sekolah Menengah Kebangsaan Panji Alam (SMKPA), East Coast Environmental Research Institute (ESERI), University College Terengganu Advanced Technical Institute (UCTATi) for analysis support and Noor Arfa Batik \& Craft Centre for their support and sponsor towards completing this project.

\section{Funding}

None.

\section{Conflicts of interest}

The author declares no conflict of interest

\section{References}

1. Abdullah R. These 51 polluted rivers in Malaysia. Astro Awani. 2018.

2. Mohamed RMSR, Nanyan NM, Rahman NA. Colour removal of reactive dye from textile industrial wastewater using different types of coagulants. Asian J Appl Sci. 2014;2(5):650-657.

3. El Messiry M, Aloufy A, Elmor M. Assessment of nanofibers filtration for textile waste-water treatment. J Appl Mech Eng. 2016;5(3):1-8.

4. Wang Z, Xue M, Huang K, et al. Textile dyeing wastewater treatment. Adv Treat Text Effl. 2011;5:91-116.

5. Conceição V, Freire FB, de Carvalho KQ. Treatment of textile effluent containing indigo blue dye by a UASB reactor coupled with pottery clay adsorption. Acta Sci Technol. 2013;35(1):53-58.
6. Ntsapi M, Tubatsane B, Machachamise L, et al. Exploration of the local clay in removing the blue textile dye from the blue stream commonly known as 'mabolou running through thetsane industrial area, maseru. Int J Waste Resour. 2018;8(340):2.

7. Suteu D, Zaharia C, Muresan A, et al. Using of industrial waste materials for textile wastewater treatment. Environ Eng Manag J. 2009;8(5):1097-1102.

8. Kallman EN, Oyanedel-Craver VA, Smith JA. Ceramic filters impregnated with silver nanoparticles for point-of-use water treatment in rural Guatemala. J Environ Eng. 2010;137(6):407-415.

9. Nair C, Kani K. Effectiveness of Locally Made Ceramic Water Filters for Household Water Purification. Int J Emerg Technol Adv Eng. 2017;7(1):75-82.

10. Yakub I Plappally A, Leftwich M, et al. Porosity, flow, and filtration characteristics of frustum-shaped ceramic water filters. J Environ Eng. 2012;139(7):986-994.

11. Viana CEM, da Silveira Neto JW, Mourad KA. Using rice husks in water purification in Brazil. Int J Environ Plan Manag. 2016;2(3):15-19.

12. Ajayi BA, Lamidi YD. Formulation of ceramic water filter composition for the treatment of heavy metals and correction of physiochemical parameters in household water. Art and Design Review. 2015;3:94-100.

13. Mohammed Z. No more clean water from the Skudai River. BH Online. 2016 .

14. Fersi C, Gzara L, Dhahbi M. Flux decline study for textile wastewater treatment by membrane processes. Desalination. 2009;244(1-3):321332.

15. Shivaraju HP, Egumbo H, Madhusudan P, et al. Preparation of affordable and multifunctional clay-based ceramic filter matrix for treatment of drinking water. Environ Technol. 2019;40(13):1633-1643.

16. Sutedja A, Josephine CA, Mangindaan D. Polysulfone thin film composite nanofiltration membranes for removal of textile dyes wastewater. Presented at the IOP Conference Series: Earth and Environmental Science. 2017;109:012-042.

17. Shahadat M, Isamil S. Regeneration performance of clay-based adsorbents for the removal of industrial dyes: a review. RSC Adv. 2018;8(43):24571-24587. 